\title{
Mathematics as Discourse
}

\author{
Matemática como Discurso
}

Ole Skovsmose*

\begin{abstract}
Initial steps are taken towards an interpretation of the discourse of mathematics, by showing that a mathematical model does not represent, but re-present; that it is not objective, but that it invents its objects; and that it is not descriptive, but performative. Mathematics-based discursive acts become identified, as crucial elements in an interpretation of mathematics as discourse. The discursive acts are: (1) technological imagination, (2) hypothetical reasoning, (3) legitimation or justification, (4) realisation, and (5) dissolution of responsibility. Through such acts, mathematics exercises symbolic power and makes possible new forms of symbolic violence.
\end{abstract}

Keywords: Analytic Duality-Interpretation of Language. Discursive Interpretation of Language. Discursive Acts. Symbolic Power. Symbolic Violence.

\section{Resumo}

Os passos iniciais para uma interpretação do discurso da matemática são considerados, mostrando que um modelo matemático não representa, mas re-apresenta; que não é objetivo, mas que inventa seus objetos, e que não é descritivo, mas performativo. A matemática baseada em atos discursivos se identifica como os elementos cruciais para uma interpretação da matemática como discurso. Os atos discursivos são: (1) imaginação tecnológica, (2) Raciocínio hipotético, (3) legitimação ou justificação, (4) realização, e (5)

\footnotetext{
* Doctor in Mathematics Education, Royal Danish School of Educational Studies, Copenhagen, Denmark. Professor Emeritus at Department of Learning and Philosophy, Aalborg University, Sohngaardsholmsvej 2, DK-9000 Aalborg, Denmark. Professor Voluntário at Universidade Estadual de São Paulo (UNESP), Rio Claro, SP, Brazil. Endereço para correspondência: Departamento de Matemática, Av. 24-A, 1515, Bela Vista, CEP:13506-700, Rio Claro, SP, Brasil. E-mail: osk@learning.aau.dk.
} 
dissolução de responsabilidade. Por meio de tais atos, a matemática exerce o poder simbólico e torna-se possível nova forma de violência simbólica.

Palavras-chave: Analítica Dualidade da Interpretação da Linguagem. Interpretação Discursiva da Linguagem. Atos Discursivos. Poder Simbólico. Violência Simbólica.

\section{Introduction}

Statements can be revealing; postulates can be challenging; questions can be amusing. Statements includes acting: One can express doubt, superiority, uncertainty, anger, affection, etc. One can do a variety of things through speechacting. However, there are limits, as the grammar of language guides this acting. Here grammar has to be understood broadly, not only as a set of rules for formulating correct sentences, but also as a deep-grammar which embodies a world view. Thus what can be said depends on assumptions, ideas, and presumptions that might be engraved in the structure of language. A language provides formats for what can be expressed and thought.

When one wants to keep all such language complexities in mind one may talk about discourses. There are political discourses, racist discourses, and religious discourses. There are discourses when one is dealing with used cars, when doctors talk with patients; when teachers talk about students. Discourse shapes actions, and simultaneously it may include a range of questionable assumptions. A discourse cannot be assumed to provide a neutral representation of a domain in question. It represents a way of talking about it, a way of perceiving it, and a way of acting with respect to it. In fact, a discourse is part of the constitution of the domain itself. A discourse not only constitutes a world view, it constitutes the world as well. A discourse annihilates the distinction between the discursive and non-discursive, as discursive structures turn real.

\section{Mathematics}

In the following I want to show that it makes sense to consider mathematics a discourse. Naturally, this does not imply that mathematics needs to be only a discourse. But whatever else mathematics might be, we now concentrate on seeing it as discourse.

Mathematics can refer to school mathematics, engineering mathematics, applied mathematics, everyday mathematics, academic mathematics, and various 
forms of ethnomathematics. Any such form of mathematics can be seen as discourse. However, in the following I will concentrate on mathematical modelling as applied in engineering, economics, management, business, etc., meaning that I will concentrate on mathematics as part of technology, having a broad interpretation of technology in mind.

Together with Keiko Yasukawa and Ole Ravn (Christensen) I have worked out examples illuminating the formatting power of mathematics and mathematics in action. We have discussed how mathematical models provide strategies for overbooking, and for companies' pricing policies and marketing in general; how mathematics is crucial for modern cryptography, and for defining 'trust' in general; how mathematics provides interpretations of the ecological state of the world; how mathematics composes part of the prossessing of knowledge and information; how mathematics has become a defining element of modern warfare. Such examples bring us towards an interpretation of mathematics as discourse. ${ }^{1}$

In the following three sections, I will explore such an interpretation of mathematics by showing that mathematical modelling does not represent, but re-present; that modelling is not objective, but that it invents its objects; and that it is not descriptive, but performative. These three sections are partially overlapping: in fact one can see them as making the same point in slightly different ways. Regardless, they serve as preparation for characterising mathematicsbased discursive acts, which embody the crucial elements in an interpretation of mathematics as discourse. This brings us, in the final section, to address symbolic power as exercised through mathematics.

\section{Modelling does not represent, it re-presents}

A certain terminology has been developed with respect to mathematical modelling, often supported by a schematic illustration including four elements. The first element is reality, repeatedly depicted as a nice cloud. This reality includes a problem that needs to be addressed. The next element in the illustration is the mathematical model through which the cloudy reality is represented. This model is often depicted as a squared box, indicating that the model includes a range of simplifications. The third element in the figure is squared as well, and it

\footnotetext{
${ }^{1}$ See, for instance, Christensen, Skovsmose and Yasukawa (2009); Skovsmose and Yasukawa (2009); and Skovsmose and Ravn (2011). My previous writings about the issues are, for instance, found in Skovsmose (2005, 2009, 2010a, 2010b).
} 
represents the calculations based on the mathematical model: this is the identified mathematical solution to the problem. The fourth and final element is a bit cloudy as well; it refers to the real solution to the problem based on an interpretation of the mathematically calculated solutions. Naturally, modifications of the model are necessary, and the modelling process could include many loops.

This schematic illustration can be called the canonical portrayal of mathematical modelling. I am not going to say that this is basically wrong. But I find that this portrayal provides a simplified perspective on the modelling process. Let me point out one particular feature of this simplification related to the notion of representation.

The notion of representation includes a range of philosophical assumptions, some of which can be related to Descartes' outlook and to his rationalist approach in general. Descartes claimed that the world was composed of two different substances, namely res cogitans and res extensa. Res extensa stands for the material world, while res cogitans represents the human spirit. Thinking and knowledge belongs to res cogicans, while res extensa remains passive. How then to think about reality? How to formulate knowledge about reality? According to Descartes, a representation is necessary. Elements of the material world need to be represented by symbols in res cogitans in order to be part of intellectual processes and rational thinking about reality. Knowledge about reality depends on representations.

Out of this matter-mind dualism developed a particular understanding of language according to which language is a flexible medium for representation. Descartes was not addressing language in any explicit way. This was to come later. But still we can see an understanding of language as emerging from his dualism. The two basic assumptions of this understanding are: (1) Language and reality are two independent entities; thus reality is not affected by being represented by language. (2) An affinity can be established between reality and language, as language can provide a more or less accurate representation of reality. These two assumptions have accompanied rationalism and its further ramifications; they have played a crucial role in analytic philosophy (which we will return to later); and they are assumed in much research, particular within the natural sciences. For short, I choose to refer to these two assumptions as defining for the analytic duality-interpretation of language. According to this, language first of all provides descriptions.

This duality-interpretation also composes part of the canonical portrayal of mathematical modelling. Reality is passive and given, while the model is flexible 
and can be accommodated to reality. Naturally, the canonical portrayal does not assume that a model provides any 1-1 representation of reality: it provides a partial representation that can be improved through several iterative loops. Thus the canonical portrayal assumes a model-reality affinity that at least can be gradually improved during a modelling process.

My suggestion is not to avoid using the term representation, but to use it without assuming any form of affinity. Thus I suggest interpreting representation as re-presentation, which means presenting in a new way. I find that a representation is without epistemic control. It could take any form and serve any purposes. We may lose sight of any form of affinity through a re-presentation. When we make a mathematical model of something, we provide a representation. Naturally, one can still talk about mathematical modelling, but I find it important not to include any canonical assumption about the existence of a degree of affinity between model and reality.

\section{Modelling is not objective, it invents objects}

Traditionally a statement has been considered objective if its truth-value is independent of any particular opinions and interests, but only depends on some observational facts. The aim of science has been claimed to be objective. Although it may not be possible to obtain complete objectivity, it remains a principle aim of any scientific investigation to try to eliminate any form of subjectivity. Through such elimination, for instance with respect to the particular conditions of the observer, one is assumed to approximate objectivity. This was the explicit aim of positivism, but has remained an aim in research reaching far beyond classic positivism.

The concern was: How to be objective? How to address reality as it is, and not as it appears? How to depict the objects as they really are? The aim was to look beyond appearance and to grasp reality. This idea was emphasised by, among others, Descartes and Galilei. ${ }^{2}$ As an illustration of his point, Galilei discussed the concept of heat, and he emphasised that the experience of heat, for instance when we burn our fingers, is very different from the really behind this experience. Galilei assumed that the underlying reality in general consists of material units that can be described in terms of shapes, numbers, positions, and

\footnotetext{
2 See, for instance, Descartes (1998) and Galilei (1957). See also Skovsmose (2009) for a discussion of the appearance-reality distinction.
} 
movements. As a consequence, the subjective experience of heat does not demonstrate any similarity with the underlying reality of heat which, however, could be described in terms of velocity of particles.

The distinction between appearance and reality applies to any natural phenomenon and is basic to the scientific outlook as proposed through the scientific revolution. We cannot expect to be able to grasp reality through its appearance. Sense experiences do not have any resemblance with the reality which stands behind the phenomena. But how to get beyond sense experiences, the emblematic form of subjectivism, and grasp what can be considered objective? If the human senses are mischievous, we need a different faculty that can ensure that we reach beyond mere appearance.

The basic claim of the scientific revolution was the underlying reality of any natural phenomena can be depicted through mathematics. Mathematics is crucial for describing shapes, numbers, positions, and movements. What our senses are missing, being trapped by the appearance of natural phenomena, mathematics can illuminate. As a consequence, mathematics can be nominated as the language of science. It provides a primary-secondary distinction by depicting what is primary (the real) and ignoring what is secondary (the appearance).

From this general understanding of mathematics it is straightforward to move on to a general celebration of mathematical modelling. This ensures objectivity, as it will tend to eliminate subjectivity from the processes of description and present things as they really are. This interpretation provides an overall metaphysics for celebrating the canonical portrayal of mathematical modelling.

I find, however, this celebration to be highly problematic. I do not see mathematics as describing any pre-exiting reality as assumed by the scientific revolution and repeated many times since then. Let me explain:

One set of questions concerning appearance and reality emerge when one tries to describe a natural phenomenon like the movements of the planets. Thus the sun appears to be moving across the heavens, and by the end of the day, it appears to sink below the horizon. In such a case it seems clear that mathematics help to reveal a reality different from the appearance of the sunrisesunset phenomena. However, mathematical modelling has been applied to all kind of phenomena, and the accompanying appearance-reality distinction might in many cases be highly problematic. Thus mathematical modelling is applied within, for instance, business, marketing, promotion, managements, decision making, and production. In such cases, mathematics also establishes a distinction 
between what to consider primary and what to call secondary. Not that there needs to be any such differentiation in advance within the domain in question. Instead a primary-secondary differentiation becomes induced through the modelling process itself. Many features become eliminated from the domain that becomes re-presented through the modelling. For instance, in modelling a production process, the workers' social context becomes eliminated. Their family life becomes relegated as secondary. What becomes nominated as primary is how they can form part of an otherwise semi-automatised production process. It is the workers as potential components in a production process that is featured as primary.

In such a case, mathematical modelling does not simply depict what is primary and what is secondary: instead it nominates something as primary and ignores other things as secondary. One cannot assume the existence of such priorities in advance, but they become created during the mathematical modelling. Prioritisation forms part of the construction of the model. This means that things become re-presented, and maybe more than that. The reality that is modelled may in fact become formed through the modelling process. The worker as a component of an automatic process is not really there in advance; the workers become configured as mechanical components. They turn into objects due to the modelling process. ${ }^{3}$

A mechanical world view becomes imposed on reality, due to the mathematical modelling. It becomes established through the primary-secondary priorities that accompany mathematics. A mathematical model is not at all objective, as claimed by the classical portrayal, but rather constitutes the objects of the modelling process in a particular format. The underlying reality for a modelling process becomes an invented reality. It was not there waiting in advance; instead it emerged as part of the mathematical modelling.

\section{Modelling is not descriptive, but performative}

According to the classic portrayal, modelling has been presented as a descriptive process. However, emphasising that modelling means re-presenting, and that it produces its objects, bring us to the idea that modelling means acting. Modelling is not descriptive but performative. This idea resonates with a general move in the philosophy of language away from the analytic duality-interpretation.

\footnotetext{
${ }^{3}$ See Skovsmose (2012) for a further discussion of robotting and surveilling.
} 
However, let us start by taking one more look at this duality-interpretation, which was particularly elaborated within analytic philosophy. In his Begriffschrift from 1879 , Frege, provided the philosophy of language not only with a range of new ideas but also with an extreme degree of analytic exactness. The overall idea is condensed in the title, Begriffschrift. Directly translated, Begriffschrift means "concept writing": Begriff means "concept", and schrifft means "writing". What Frege had in mind was a language that provided an exact basis for addressing concepts. This language took the form of formal logic, in particularly apt for formulating set theory - and sets were seen by Frege as concepts. This language was further developed by Russell and Whitehead in Principia Mathematica into a proper foundation for mathematics, while Wittgenstein in Tractatus gave it a unique role to play in his picture theory of language. According to this theory, language is picturing reality. Like any other map, a language could provide a more or less accurate picture. Language was creating a map, where one can see the 1-1 mapping as an extreme ideal. An assumption, also formulated by Wittgenstein, was added to the picture theory, namely that some languages are doing better mapping than other languages, and that the ultimate mapping, from a scientific perspective, was ensured by formal languages. I see Wittgenstein's picture theory from Tractatus as a principal formulation of the analytic duality-interpretation of language. Languages, in general, provide descriptions, and formal languages, in particular, provide descriptions that are appropriate for scientific enterprises.

However, the analytic duality-interpretation has been confronted by other interpretations of language. A provisory speech act theory was formulated by Austin. According to him, a statement has a locutionary content, an illucutionary force, and a perlocutionary effect. As an example, we can consider the statement: the worker could do his job faster. The locutionary content refers to the content of the statement: the speed of the particular working process. The illucutionary force refers to the power of the statements; for instance, when made as part of a management investigation, the statements can be turned into new demands to the workers. Finally, the statement has a perlocutionary effect, thus many workers might feel threatened by the statement. Austin's point is that any statement includes these three features. This way Austin confronts any analytic dualityinterpretation of language. ${ }^{4}$

\footnotetext{
${ }^{4}$ See Austin $(1962,1970)$. During the same period Wittgenstein, in Philosophical Investigations, elaborated his ideas about language games, and such games also include actions. Thus Wittgenstein himself provided a radical negation of the duality-interpretation of language.
} 
The speech act theory became further developed by Searle, whose 1969 book is in fact entitled Speech Acts. From then on speech act theory proliferated. Discourse theory is one important feature of this proliferation, elaborating the performative aspects of languages. However, one should talk about discourse theories, as the social, political and cultural ways of contextualising speech acting have been elaborated in many different ways. ${ }^{5}$ Discourse theories have been developed by Laclau, Mouffe, Žižek and many others. Žižek's book Violence from 2008 shows the profoundness of symbolic violence, which is still an example of linguistic performances. It also needs to be remembered that in a range of studies Foucault pointed out the network of power structures that are integrated into scientific discourses. Much inspiration for the development of discourse theory has emerged from his work.

Supported by Austin, Searle, Laclau, Mouffe, Foucault, Žižek, and many others most analytic duality-interpretation of language has been left behind. We have moved towards a discursive interpretation of language, which we can try to summarise in the following way: (1) Reality and language are not independent entities; they are dialectically connected. Thus reality is formed through discourses (although not necessarily only through discourses); and as multiple discourses can be operating, it is more appropriate to talk about realities in plural. (2) It is not possible to establish any affinity between reality and language, and any talk about language representing a reality is an illusion. Any so-called representation includes priorities and assumptions; it includes a reformulation according to certain assumed world views. These two assumptions express the idea that language is not just descriptive but also performative. Actions can be accomplished through language.

This shift from a duality interpretation to a discursive interpretation of language also concerns mathematical modelling. Modelling can be interpreted in terms of performance, as a form of speech acting. One could initiate a study of this acting by considering what could be the locutionary content, the illucutionary force, and elocutionary effect of mathematical modelling. Such a study could be conducted with reference to any example of mathematical modelling. There are, however, other ways of leaving behind any analytic duality-interpretation of mathematical modelling. Previously I have explored the formatting power of mathematics ${ }^{6}$, but now I see these studies as generalised into studies of

\footnotetext{
5 See, for instance, Torfing (1999).

${ }^{6}$ See, for instance, Skovsmose (1994).
} 
mathematics in action. However, there is a huge task ahead of us in developing a proper discourse theory with respect to mathematics. Such a theory would not only be a significant contribution to the philosophy of mathematics, it would also ensure a crucial development of discourse theory itself, which up to now has ignored formal languages. ${ }^{7}$

\section{Mathematics-based discursive acts}

We have highlighted that a mathematical model does not represent, but rather re-presents, that it is not objective, but instead invents its objects, and that it is performative ${ }^{8}$. This brings us forward to the point that mathematical modelling can be more adequately addressed through a discursive interpretation of language.

After this observation, we are ready to characterise mathematics-based discursive acts. They represent the crucial elements in an interpretation of mathematics as discourse. As already indicated, such discourses operate in, for instance, engineering projects, economic strategies, organisational schemes, management principles, administrative procedures, business plans, and taxadministrations. However, the discussion of mathematics-based discursive acts can be pursued in other directions as well. One can consider discursive acts associated with any form of ethnomathematics, street mathematics, everyday mathematics, etc.

Let me just summarise the mathematics-based discursive acts, as I have presented them previously. ${ }^{9}$ Thus, I highlight the performative aspects of mathematics (at least some forms of mathematics) by commenting on (1) technological imagination, (2) hypothetical reasoning, (3) legitimation or justification, (4) realisation, and (5) dissolution of responsibility.

Technological imagination. An important feature of technological development is the conceptualisation of new possibilities. Such a conceptualisation is a discursive act. The space of possibilities is an expression of what could be called technological imagination, which is crucial for any form of technological innovation. For any technological construction it is important to provide a blueprint of what is to be constructed. Mathematical models operate as such blueprints;

\footnotetext{
${ }^{7}$ In Skovsmose and Ravn (2011), we are exploring such new developments in the philosophy of mathematics.

${ }^{8}$ Several studies of mathematical modelling show a movement toward this deeper understanding. See, for instance, Barbosa (2006); and Jablonka (2010).

${ }^{9}$ See, for instance, Skovsmose (2011).
} 
not by reproducing something that exists, but by modelling something that one might be able to produce. In all forms of technology, mathematics-based imagination opens spaces of possibilities. As paradigmatic examples of such mathematical blue-print imaginations, one can refer to the conceptualisation of the computer, the construction of the Internet, the proliferation for new forms of communication technologies, the implementation of technologies of surveillance, etc. Within such domains, there is no commonsense-based imagination equivalent to a mathematics-based imagination. In general, technological development starts from a space of possibilities that is endlessly recast through mathematics-based imagination.

Hypothetical reasoning is of the form, "if $p$ then $q$, although $p$ is not the case". Such counterfactual reasoning is essential in any kind of technological enterprises. If we do $p$, what would be the consequence? It is important to address this question before we in fact do $p$. Is a certain technological design feasible?

Hypothetical reasoning normally presupposes the use of elaborate mathematical models. Through an investigation of a mathematical blue-print of a possibility, one tries to identify the implications of actually carrying it out. However, the implications that are identified by investigating the mathematical blue-print are not real-life implications; they are just calculated implications. It is far from obvious what the relationship may be between calculated implications and real-life consequences of carrying out a technological enterprise. This observation applies to the implementation of any form of technological enterprise. The huge gap between calculated implications and real-life consequences provides a titanic entrance into the risk society. This is one example of where mathematicsbased discursive acts could take us.

Legitimation or justification. Discourses are brought in operation when we try to justify or to legitimate something, being a statement, an action, a decision. A discourse represents a world view, which provides resources for both legitimation and justification.

According to a classic philosophical perspective, justification refers to a genuine logical support of, say, an action while legitimation might include dubious elements, for instance by serving particular interests. The point of providing legitimation for an action is to make it appear as if it is justified. However, it might only be within an idealised philosophical framework that it is possible to distinguish between legitimation and justification. Discourses can be of various forms, and they might liberally support both proper and imaginary arguments. 
Mathematical models provide discourses for both justification and legitimation. Furthermore, they might blur any such distinction. It has been pointed out that in much decision-making, for instance concerning the implementation of a new health care programme, mathematical modelling plays an active part in identifying potential implications. A broad spectrum of mathematics-based hypothetical reasoning is established in order to point out pros and cons with respect to the programme. Mathematics is crucial for any such cost-benefit analysis, which informs the decision making.

Mathematics has been assumed to be objective by providing solid arguments for a decision. But a mathematical model is not a straightforward descriptive device. Thus cost-benefit analysis concerns a population which is shaped through the modelling. It is not a real-life population but a systematised one. What to call costs, what to call benefits, and how to measure them, are all model-created measures. In general, modelling includes an invention of the object that becomes addressed. Thus, the pro and con argument, related to, say, the health-care programme, becomes situated in a model-invented reality.

Realisation. One point of discourse theory is that the distinction between the discursive and the non-discursive evaporates. What is considered reality becomes recast through discourses about reality. Philosophically speaking, one can claim that Descartes' distinction between res cogitans and res extensa becomes abolished. Reality becomes reworked through language, which in turn is formed through social practices. Reality includes materialised discourses. Thus Gellert and Jablonka (2009, p. 20) emphasise that mathematics-based decisions operate on many levels:

On the level of national policy, decisions about the distributions of state salaries, pensions, and social benefits rely on mathematical extrapolations of demographical and economic data .... On the level of interpersonal relations, mathematics-based communication technologies have already changed the habits and styles of private conversations.

And one could continue and refer to: management principles, administrative procedures, organisational schemes, business plans, health care programmes, military operations, etc. In all such domains mathematical procedures that might have been introduced as analytic devices now take the form of real-life operating decisions.

Our life-worlds are formed through categories and discourses, many of 
which emerge through mathematical modelling. These categories and discourses are put into operation. They are working. Thus our reality includes materialised mathematical discourses.

Dissolution of responsibility. Any action raises the question: Who is responsible for what is done? This question makes clear sense when an acting subject can be located. It becomes more difficult to address when the acting subject is an institution, an organisation, a programme. But it is still possible to find ways of defining responsibility in such cases. More complicated, yet, is defining responsibility with respect to speech acting. Naturally there are procedures for locating responsibility when speech acts take the form of, say, a particular insult. But difficulties arise when we consider the general actiondimension of language. When one consider acts, as for instance emerging from a certain scientific discourse, the location of responsibility becomes difficult.

Let us again consider the situation of a rationalisation of a production process. Such a rationalisation includes a reconfiguration of the production process. But who is responsible for the implementation of the mechanical world view with respect to this reconfiguration? It is difficult to identify a particular acting subject. Somehow responsibility seems to evaporate. Could the people who constructed the model be responsible? Or could it be claimed that the very mathematical discourse, as the carrier of the mechanical world view, is responsible? Somehow discursive acts seem to be missing an acting subject. Actions based on mathematics appear to be conducted in an ethical vacuum. In this sense, a dissolution of responsibility is taking place.

There are a couple of remarks I want to add with respect to mathematicsbased discursive acts in general. What I first of all had in mind was mathematical modelling as applied in a vast area of technology. One can, however, also try to investigate mathematics-based discursive acts with reference to pure mathematics. My point would be that the notion "pure" is mischievous: there is nothing pure in the sense that mathematics composes part of a discourse without any acting dimension. Also pure mathematics is performative.

It is important to clarify the performative dimension of different forms of ethnomathematics. Thus ethnomathematics-based actions form part of a range of different cultural practices. Mathematics also forms part of everyday-actions, such as: going shopping, controlling tax-payments, making a budget, planning a holiday, etc. When such different forms of mathematics are addressed, we gain a better understanding of mathematics as discourse. 


\section{Symbolic power}

Discourses can be powerful, mathematics can be powerful, knowledge can be powerful. The intimate connection between knowledge and power also applies to mathematics. In discourse theory one refers to symbolic power, and the symbolic power of mathematics becomes realised through mathematicsbased discursive acts. ${ }^{10}$

The discussion of knowledge and power has been stimulated by Foucault's work, which I find extremely inspiring. However, Foucault concentrated on certain domains of knowledge: psychology, psychiatry, and related discourses. Nowhere did he address knowledge of the exact sciences or mathematics. However, I find that a very important domain for exploring the relationship between knowledge and power is precisely the exact sciences and mathematics.

The development of new technologies has been decorated by an optimistic vocabulary: this development has been broadcast as both necessary and positive. Technology has been nominated as the motor of progress. This is, however, not how I see things. Technological development can take any direction. It can be promising, risky, or disastrous. In whatever direction the technological development may happen to take us, it is propelled by mathematics in action. Technology is mathematics-based. It epitomizes mathematics-based symbolic power.

There are many ways the notion of ideology can be interpreted. It can refer to cultural, religious, and political ideas. Somehow an ideology represents a "world view", and symbolic power operates through such views. This also applies to mathematics-based symbolic power. A classic example can be related to the formulation of the heliocentric world view - a world view in the most direct sense of the word. The formulation of this view had a huge ideological impact, confronting religious dogmas. The heliocentric world view was constituted through mathematics. The mechanical world view that accompanied the scientific revolution is also mathematics driven, as reality is defined in terms of numbers, positions, shapes, and movements of material unites. Such a view has formed our conception of nature. A mechanical world view can, however, also be imposed on social structures - on a production process, for instance, where the workers become conceptualised as more or less well-functioning units in an assembly line. Also in this case that mechanical world view becomes facilitated through

${ }^{10}$ See Skovsmose (2010c) 
mathematics. In fact, whatever domain we consider, a mechanical world view tends to be imposed when mathematics is brought in action. This is a most important example of symbolic power routed in mathematical discourses.

It makes good sense to talk about symbolic power with respect to mathematics, but does it also make sense to talk about symbolic violence? Such violence has been addressed with respect to language in general, by thinkers such as Žižek. Discursive acts can be violent, for instance, when one imposes a label with respect to certain groups of people. A racist vocabulary can serve as a paradigmatic example of such violence. Other forms of symbolic violence become acted out through labels like: working class, lower class, deficient, primitive. Such labels compose part of different forms of discriminating discourses. Labelling often means a violent stigmatisation formed through dubious metaphysical categories.

Mathematics-based discursive acts also include possibilities for symbolic violence. Let us consider again a mathematical model for productivity. Such a model includes a range of parameters, some of which refer to people and their performances. In order to be modelled, performances have to be expressed in quantitative terms. They have to be measured. This is the paradigmatic step for turning a qualitative phenomenon into a quantitative one. As soon as it has been measured, a phenomenon can be grasped by a model. It can be compared with some stipulated standards; it can be subjected to cost-benefit analysis; it can be manipulated within the universe of calculations. The human dimensions of the workers and what they experience due to the new productive schemes have become eliminated from all calculations. Their personal experiences have been disregarded as being subjective. These experiences do not belong to the mathematics-created reality. This is an illustration of symbolic violence routed in mathematics.

This brings us to an important point with respect to social theorising, as for instance formulated by Habermas, Giddens, and Bauman. They try to address some of the principal features of social development, and they explore notions like modernity, late modernity, post modernity, liquid modernity, etc. What surprises me in their formulations is that they do not see any particular need for addressing the role of mathematics. It is not possible to come across the word mathematics in the index in any of their numerous books. In fact, many other authors trying to formulate a broad social theorising share the same ignorance of mathematics. ${ }^{11}$ For me, it is in important to make a new turn in social theorising by addressing

\footnotetext{
${ }^{11}$ As an exception let me refer to Lyotard (1984).
} 
the symbolic power that emerges though formal languages and mathematics in particular. Social theorising will be incomplete without addressing this component of the knowledge-power dialectics.

\section{Acknowledgements}

Many of the ideas I have presented here are inspired by cooperation with others, and together with Keiko Yasukawa and Ole Ravn, I have explored many aspects of mathematics in action. Furthermore, I want to thank Denival Biotto Filho, Renato Marcone, Raquel Milani, and Miriam Godoy Penteado for many suggestions for improving the paper.

\section{References}

AUSTIN, J. L. How to Do Things with Words. Oxford: Oxford University Press, 1962.

AUSTIN, J. L. Philosophical Papers. 2nd ed. Edited by J. O. Urmson and G. J. Warnock. Oxford: Oxford University Press, 1970.

BARBOSA, J. Mathematical Modelling in Classrooms: A Socio-Critical and Discursive Perspective. ZDM Zentralblatt für Didaktik der Mathematic, Eggenstein, Leopoldshafen, v. 38, n. 3, 293-301, 2006.

CHRISTENSEN, O. R.; SKOVSMOSE, O.; YASUKAWA, K. The Mathematical State of the World: Explorations into the Characteristics of Mathematical Descriptions. In B. Sriraman and S. Goodchild, (Eds.), Relatively and Philosophically Earnest: Festschrift in honor of Paul Ernest's $\mathbf{6 5}^{\text {th }}$ Birthday. Charlotte, NC, USA: Information Age Publishing, v. A volume in the Montana Mathematics Enthusiast, n. 3, p. 83-96. Sep. 2009.

DESCARTES, R. The World and Other Writings. GAUKROGER, S. (Ed.) Translation: Stephen Gaukroger. Cambridge: Cambridge University Press, 1998. (First published 1664).

FREGE, G. Begriffsschrift: A Formal Language, Modeled Upon that of Arithmetic, for Pure Thought. In: HEIJENOORT, J. V. (Ed.). From Frege to Gödel: A Source Book in Mathematical Logic, 1879-1931. Cambridge (USA): Harvard University Press, 1967. (Original German edition 1879).

GALILEI, G. Discoveries and Opinions of Galileo. Translation: Stillman Drake. New York: Anchor Books, 1957. 
GELLERT, U.; JABLONKA, E. The Demathematising Effect of Technology. In: ERNEST, P.; GREER, B. and SRIRAMAN, B. (Eds.). Critical Issues in Mathematics Education. Charlotte, NC, USA: Information Age Publishing, p. 19-24, 2009.

JABLONKA, E. Reflections on Mathematical Modelling. In: ALR $\varnothing$, H.; RAVN, O. and VALERO, P. P. (Eds.). Critical Mathematics Education: Past, Present and Future. Rotterdam: Sense Publisher, p. 89-100, 2010.

LYOTARD, J. F. The Postmodern Condition: A Report on Knowledge. Translation: Geoff B. and Brian M. foreword by Fredric J. Manchester: Manchester University Press, 1984. (Original French edition 1979).

SEARLE, J. Speech Acts. Cambridge: Cambridge University Press, 1969.

SKOVSMOSE, O. Towards a Philosophy of Critical Mathematics Education. Dordrecht: Kluwer Academic Publishers, 1994.

SKOVSMOSE, O. Travelling Through Education: Uncertainty, Mathematics, Responsibility. Rotterdam: Sense Publishers, 2005.

SKOVSMOSE, O. In Doubt: About Language, Mathematics, Knowledge and Lifeworld. Rotterdam: Sense Publishers, 2009.

SKOVSMOSE, O. Mathematics: A Critical Rationality. Philosophy of Mathematics Education Journal. Special issue on Critical Mathematics Education, 25, Oct. 2010a. Available at: <http://www.people.ex.ac.uk/PErnest/>. Accessed at: 11 June 2012.

SKOVSMOSE, O. Can Facts be Fabricated Through Mathematics? Philosophy of Mathematics Education Journal. Special issue on Critical Mathematics Education, 25, Oct. 2010b. Available at: <http://www.people.ex.ac.uk/PErnest/>. Accessed at: 11 June 2012.

SKOVSMOSE, O. Symbolic power and mathematics. In: BHATIA, R. (Ed.).

Proceedings of the International Congress of Mathematicians. Hyderabad, India: Hindustan Book Agency. 2010c. p. 690 - 705. Volume 1.

SKOVSMOSE, O. An Invitation to Critical Mathematics Education. Rotterdam: Sense Publishers, 2011.

SKOVSMOSE, O. Symbolic power, robotting, and surveilling. Educational Studies in Mathematics. Published online: Springer Science. v. 80, n. 1-2, p.119 - 132. Feb. 2012. Available at: <http://www.springerlink.com/content/53p1u4442j042121/>. Accessed at: 11 june 2012. 
SKOVSMOSE, O.; RAVN, O. Matematikfilosofi [Philosophy of Mathematics]. Århus, Denmark: Systime, 2011.

SKOVSMOSE, O.; YASUKAWA, K. Formatting Power of 'Mathematics in a Package': A Challenge for Social Theorising? In: ERNEST, P.; GREER, B.; SRIRAMAN, B. (Eds.). Critical Issues in Mathematics Education. Charlotte, NC, USA: Information Age Publishing, 2009. p. 255-281.

TORFING, J. New Theories of Discourse: Laclau, Mouffe and Žižek. Oxford: Blackwell, 1999.

WHITEHEAD, A. N.; RUSSELL, B. Principia Mathematica I-III. Cambridge: Cambridge University Press, 1910-1913.

WITTGENSTEIN, L. Tractatus Logico-Philosophicus. German text with an English. Translation: C. K. Ogden, Introduction by Bertrand Russell. London: Routledge, 1992. (First German edition 1921).

WITTGENSTEIN, L. Philosophical Investigations. Translation: G. E. M. Anscombe, 2nd Edition. Oxford: Basil Blackwell, 1958. (First published 1953).

ŽIŽEK, S. Violence. New York: Picador, 2008.

Submetido em Outubro de 2010. Aprovado em Agosto de 2011. 